МИТРОШЕНКОВ Олег Александрович - доктор философских наук, профессор кафедры ЮНЕСКО Института государственной службы; профессор кафедры управления и мировой экономики и международных отношений Института бизнеса и делового администрирования Российской академии народного хозяйства и государственной службы (РАНХиГС) при Президенте РФ (119571, Россия, 2. Москва, nр-кт Вернадского, 84, корп. 8; omitrosh6@таil.ru)

\title{
МИФОРИТУАЛЬНАЯ СИСТЕМА В ОПТИКЕ СМЫСЛОГЕНЕТИЧЕСКОЙ ТЕОРИИ КУЛЬТУРЫ А. ПЕЛИПЕНКО
}

\begin{abstract}
Аннотация. В статье рассматривается вторая часть фундаментального труда отечественного ученого-культуролога Андрея Пелипенко «Постижение истории» - «Мифоритуальная система». Книга 1. «Медиационная парадигма» (2017). Автор применяет свою смыслогенетическую теорию культуры к анализу общих и системных характеристик мифоритуальной системы - первой из двух полностью реализовавшихся в истории культурных макросистем. В книге интерпретируется коэволюция имманентного развития человека как культурного существа и его внешней коллективной истории - истории системноинституциональных структур культуры. Анализ осуществлен на основе медиационной парадигмы, обращающейся к квантовой механике, к космологическому, биологическому, нейрофизиологическому и психическому срезам реальности. Ключевыми положениями медиационной парадигмы являются концепты онтологического статуса запредельного мира и полевых свойств культуры.

Автор камня на камне не оставляет от парадигматики общенаучного дискурса, позитивистской по своей сути и отражающей, несмотря на оснастку новейшими постнеклассическими идеями, взгляд на мир XIX в. с присущими ему предрассудками вульгарно-механистического рационализма.
\end{abstract}

Ключевые слова: культура, смысл, смыслогенетическая теория, мифоритуальная система, медиационная парадигма, психосферная медиация, импликативный мир, запредельный мир, культура как полевое образование, миф, ритуал, мифоритуальный пространственно-временной континуум, магема

$\mathrm{B}$ 2015 г. я написал обзорную рецензию на книгу А.А. Пелипенко «Постижение культуры». Ч. 1. «Культура и смысл» [Пелипенко 2012]. В ней (рецензии) была кратко проанализирована авторская смыслогенетическая теория культуры. Исключительно высокая оценка этого труда (которая с тех пор только укрепилась) сопровождалась надеждой, что продолжение этого яркого и эвристически чрезвычайно содержательного исследования непременно состоится, поскольку автор намеревался написать еще четыре подобных его части, и что оно определенно не разочарует его читателей [Митрошенков 2015а; 2015б].

В принципе и отчасти так оно и получилось. В 2017 г. в свет вышла первая книга - «Медиационая парадигма» - 2-й части этого фундаментального исследования А.А. Пелипенко под названием «Мифоритуальная система». Выход в свет этой части, как и первой, безусловно, обогатил отечественную и мировую гуманитарную науку и принес удовлетворение вдумчивым исследователям и почитателям таланта автора.

Трагизм ситуации, однако, заключается в том, что это издание вышло после безвременного и неожиданного ухода из жизни А.А. Пелипенко в декабре 2016 г. Ему было всего 56 лет... Помимо того, что автору не довелось увидеть это издание, мировая наука и человечество лишились возможности ознакомиться с предполагавшимся дальнейшим продолжением и результатами этого 
выдающегося исследования ${ }^{1}$, которое, без сомнения, опережает свое время и оставляет далеко позади современную парадигматику общенаучного дискурса, позитивистскую по своей сути и отражающую, несмотря на оснастку новейшими постнеклассическими идеями, «взгляд на мир XIX века с присущими ему предрассудками вульгарно-механистического рационализма и его любимого дитя - химеры утилитаризма» [Пелипенко 2017: 19].

Выход этой книги, несомненно, делает честь тем людям, которые приложили немало усилий для того, чтобы собрать необходимые материалы, придать им научную и композиционную целостность, - прежде всего сотрудникам издательства «Политическая энциклопедия» и Президентского центра Б.Н. Ельцина. Остается надеяться, что, возможно, им все же удастся издать вторую книгу этой же второй части, а может, даже и третью часть исследования - уж очень не хочется расставаться с выдающейся эвристикой и креативностью А.А. Пелипенко!

Однако обратимся к собственно книге.

Автор объясняет, почему он обращается к мифоритуальной системе культуры (далее - МРС), которая представляет собой одну из двух полностью реализовавшихся в истории культурных макросистем. МРС - колоссальный по протяженности и значению этап эволюции культуры и самого человека. Доисторическим прологом МРС выступают первобытные (архаические) культуры. Верхний палеолит, открывая эпоху архаики, знаменует обретение культурой своей раннесистемной стадии, развитие которой происходило во времена неолита и ранних цивилизаций классического Востока. Закат МРС приходится на рубеж II І тысячелетий до н.э., когда в результате начавшейся дуалистической революции утвердилась новая макроисторическая система - логоцентрическая. В последующую эпоху МРС существовала как витальный фон (материнская система) для ее развития. На этом этапе историческая динамика МРС представляет собой сложное переплетение адаптирующего (горизонтального) доразвития с деградацией и эрозией; о господстве мифоритуальных практик говорить уже не приходится, как и о безраздельном доминировании мифа в мышлении. Впрочем, влияние мифоритуальных практик на пришедшую им на смену социокультурную реальность до конца не выявлено и не изучено [Пелипенко 2017: 15].

Обращение к анализу МРС требует решения главного вопроса фундаментальных исследований культуры: как коррелируют между собой когнитивные схемы сознания и надындивидуальные конструкции культуры, для которой индивид или группа - не более чем элемент ее системно-организмической структуры? Иными словами, как осмыслить главное противоречие бытия человека в культуре - между исторически возрастающей человеческой самостью и инструментальным использованием человека культурой в ее собственных целях? При этом смыслы, которые человек переживает как свои экзистенциальные, также, разумеется, задаются не чем иным, как культурой. Непонимание этого порождает, по мнению А. Пелипенко, самую, пожалуй, глубокую и устойчивую из присущих человеку иллюзий, питающую химеру свободы. Ведь в сознании и жизненном мире человека эти культурно заданные смыслы приобретают специфически человеческое измерение, иное по отношению к культурно-историческому [Пелипенко 2017: 9-10].

В связи с этим возникает диалектическая ситуация, продуцирующая 2 принципиально неразрешимых противоречия исторического бытия: между 1) гло-

1 На мой субъективный взгляд, исследование А. Пелипенко «Постижение культуры» даже в столь незавершенном виде - самое яркое, масштабное, глубокое и оригинальное явление в отечественном и мировом социально-гуманитарном знании за последние несколько десятилетий. 
бальным и локальным и 2) социальным и индивидуальным началами. А в общем контексте - между человеком и культурой. Формы и способы ситуационного разрешения этих противоречий определяют историческую специфику и контуры любой локальной культурной системы (далее - ЛКС).

С целью связать в общем контексте эволюции культуры психическое/ментальное начало с историческим А. Пелипенко на основе своей смыслогенетической теории культуры выдвигает медиационную парадигму, в русле которой интерпретирует коэволюцию имманентного развития человека как культурного существа и его «внешнюю» историю - историю системно-институциональных структур культуры. Интерпретация эта основана на обращении к сферам, традиционно не относящимся к социально-гуманитарному знанию, прежде всего к современной квантовой механике, и приложении ее выводов к таким срезам реальности, как космологический, биологический, нейрофизиологический и психический. Обосновываются также два ключевых положения медиационной парадигмы - концепты онтологического статуса запредельного мира (разд. I, гл. 2) и полевых свойств (разд. I, гл. 3) как культуры вообще, так и любой ее регионально-исторической версии [Пелипенко 2017: 10].

Повсеместная распространенность в древности человеческих жертвоприношений, в т.ч. добровольных, неизмеримо более низкая по сравнению с ритуалами ценность человеческой жизни, вообще весь строй бытия недвусмысленно указывают на перманентное взаимодействие людей с запредельным, которое и выступает сверхценностью культуры, ее имманентной целью и способом существования. Тысячелетиями люди строили свою жизнь на основе мифоритуальных практик и традиций, бросая большую часть доступного им ресурса на возведение святилищ и храмов, соотнося свои намерения и поступки не с рациональными резонами, а с сакральными прецедентами и сигналами из запредельного мира. Непредставимо долгое время любые мысли и действия людей в их посюсторонней жизни адресовались неким потусторонним силам и уже оттуда «спускались на землю», получая санкцию на «здешнее существование». Механистический же рационализм (автор подвергает его сокрушительной критике) предписывает не замечать того, что десятки тысяч лет мифоритуальным и магическим практикам люди посвящали основное свое время и жизненные силы, а экзистенциальные основания черпали в сопричастности к запредельному, но не в способах ведения хозяйства [Пелипенко 2017: 23-24].

Если культура - самоорганизующееся системное образование, встроенное в эволюционную пирамиду Вселенной, то для нее, как и для всякой иной системы - что неорганической, что биологической, - фундаментальной витальной задачей выступает продуктивная медиация с трансцендентным миром, где имплицитно содержатся паттерны всех возможных состояний и событий. Среди доступных умозрению уровней реальности этот мир - самый фундаментальный. Если коротко, сущность медиации между мирами заключается в том, что любые структуры и образования эксплицитного (посюстороннего) мира посредством интенциональных взаимодействий вызывают из импликативного мира (далее - ИМ) свое измененное существование в каждый момент (квант) времени. Импликативный и эксплицитный миры находятся в отношениях инобытийственности и глубочайшей взаимной скоррелированности. Первичность ИМ по отношению к миру эмпирическому сквозным мотивом пронизывает культурное сознание, проявляясь то в мифосемантике судьбы и предопределенности событий, то в религиозной или мистической метафизике предсуществования и т.д. [Пелипенко 2017: 25].

Медиация между мирами охватывает все процессы во вселенной и осуществляется в своего рода буферной зоне - психосфере. В ней располагается шкала 
онтологических состояний, соответствующих разным уровням сворачивания и разворачивания паттернов ИМ. На одном конце этой шкалы - чистая потенциальность, имеющая ничтожно малую вероятность воплощения. На другом - квантовые энграммы однажды уже воплощенных феноменов, причем вероятность повтора таких событий, в измененном, разумеется, виде, наиболее высока. Богатому набору промежуточных состояний - уже не чистых потенций, но и еще не феноменов - соответствует столь же богатый набор форм перцепции их человеческой психикой: от интуитивных предчувствий и сновидений до визионерства и разнообразных экстрасенсорных перцепций в измененных состояниях сознания.

Для культуры и для МРС в первую очередь эти перцепции имеют не периферийное, а основополагающее и системообразующее значение. Таким образом, ментальной «подкладкой» любых культурных практик выступает психосферная медиация (далее - ПМ), благодаря которой и осуществляется разворачивание ЛКС в историческом времени. Бытие человека в культуре - это пребывание его в мире инобытийственных проекций паттернов, среди которых связанные с программами жизнеобеспечения занимают довольно скромный сектор, хотя аберративное его преувеличение в утилитаристской парадигме имеет, разумеется, вполне объяснимые причины. Чисто утилитарные мотивации, развивающиеся параллельно с десакрализацией технологических процессов, утверждаются медленно, подспудно, периферийно. И потому чисто факторный анализ древних (не говоря уже о первобытных) обществ, основанный на подчинении всех сфер культуры задачам физического и социального обеспечения, порождает чудовищно искаженную картину [Пелипенко 2017: 26].

МРС - первая система, полностью реализовавшая себя в истории. Ее начало и конец отмечены двумя переходами. Первый, межсистемный - от природы к культуре и второй, внутрисистемный, т.е. в масштабе культуры как целого, - от МРС к логоцентрической. Между этими переходами - огромная по протяженности и значению эпоха, в которую формировались базовые основания человеческой ментальности и самой культуры. Основания эти сохраняются и в последующие исторические эпохи, какие бы напластования исторического опыта на них ни наслаивались. Понять сущность МРС - значит постичь специфику осуществляемой ею ПМ, которая определяет все ее внешние проявления. Под этим углом зрения и миф, и ритуал предстают не просто важными феноменами культуры и даже не основой системы древнего мышления в целом, но прежде всего - присущей МРС формой медиации с миром свернутого порядка.

Понимание культуры как медиации с запредельным миром не следует связывать с религиозной философией, рассуждающей о том, что история - это будто бы диалог человека с Богом, и когда этот диалог прекратится, прекратится и человеческая история. Культура же - язык, на котором этот диалог осуществляется. Запредельный мир (мир свернутого, импликативного порядка) - это не монотеистический Бог с присущими ему атрибутами. Это совершенно иное. Хотя есть и нечто общее. Как источник всякого бытия, ИМ, как и творящий Бог, отделен от «тварного мира» непроходимой границей инобытийственности. А потому столь же протеистичен и столь же недоступен познанию.

Смыслогенетическая теория утверждает, что распространенная дихотомия «существует/не существует» в отношении запредельного мира несостоятельна. Необходим более тонкий и дифференцированный подход. Такова концепция ПМ, предполагающая развернутую шкалу онтологических состояний между умозрительными крайностями «абсолютно объективного» существования и несуществования и всерьез принимающая во внимание проблему запредельного, а также доступные сознанию режимы и уровни трансцендирования. 
А. Пелипенко подробно разворачивает онтологические и гносеологические основания исследования МРС, подвергая на этом пути жесткой критике факторные утилитаристско-прагматические, экосистемные и вообще природные подходы (особенно географические), а также позитивистско-сциентистские парадигмы. Он характеризует смыслогенетическую позицию в отношении понимания истории и, в частности, МРС как реконструктивистскую. При отсутствии достаточного фактического материала реконструкция, разумеется, уступает в валидности основанному на точных фактических данных моделированию. Однако даже умозрительная реконструкция все же лучше, чем отсутствие любой реконструкции вообще. Иначе в ход идут интерпретации в модернизаторском ключе. Относительно реконструкции не следует строить иллюзий, но и излишнего скепсиса также быть не должно. Надо лишь отказаться от претензий на «окончательное» знание, признав его относительность и неполноту.

На пути к реконструкции МРС необходимо прежде всего реконструировать ментальный контекст. Если признать, что любые социокультурные практики, в т.ч. и бессознательные, имеют в своей основе те или иные фигуры мышления, то это означает, что мышление не просто «отражает» некую неизменную объективную действительность, но и непосредственно формирует ее. Однако мышление «отслаивает» от онтологических субстратов вещей лишь те модусы, которые способно осмыслить и наделить значением, т.е. те аспекты реальности, которые для мышления необходимы и доступны. О том, чтобы прорваться к онтологическим субстратам вещей непосредственно, минуя субъективирующие фильтры сознания, давно пора забыть, как пора забыть и метафизику «объективной реальности». Речь может идти лишь о конфигурации рамок, в которых реальность условно принимается за объективную. Применительно к культуре всякие разговоры об объективной реальности как о чем-то «несдвигаемо окончательном» несостоятельны. Культурно-историческая реальность никогда не существует вообще, но всегда только как реальность-для-... Под многоточием здесь подразумевается тот или иной тип сознания и шире - ментальный тип. Поэтому путь к вещам, культурным феноменам и их отношениям лежит через реконструкцию этого самого ментального типа человека или ментального контекста эпохи.

В мифологическом мышлении нет навсегда установленных и застывших «весовых» отношений между смыслами, программами поведения и их элементами. Один и тот же фактор в зависимости от ситуации может порождать разные следствия, а действия, нацеленные на некий предполагаемый результат, могут приводить к последствиям, которые по своей значимости неизмеримо превосходят изначальную цель. При изменении контекста все может мгновенно поменяться местами.

Человек МРС, в отличие от человека более поздних эпох, преимущественно мыслит в логике не причинно-следственных связей, а диффузных и многозначных семантических комплексов (см. гл. 1 раздела II). Именно они играют определяющую роль в смыслообразовании, а не каузальность. Для человека МРС рационально-логический сектор мышления занимает примерно то же место, что для человека современного - интуиция. Внутри семантических комплексов любые связи ситуационны, нелинейны и вариативны. Свидетельство тому - полиморфизм мифа, особенно в архаике. Всякая доминативность смысла внутри комплекса контекстуальна. Кристаллизация/нуклеаризация устойчивых смысловых структур в области сакральных традиций (ядра культуры), разумеется, происходит, но по законам, отличающимся от привычных современному человеку с их главной мыслью (целью, причиной, результатом и т.Д.). 
В мифоритуальном мышлении смыслообразование происходит в режиме переменной доминативности, и это требует особых подходов к ее изучению. Важным обстоятельством при анализе МРС А. Пелипенко считает также гетерогенность исторического времени, которая не может сводиться к тривиальной констатации его перманентного уплотнения. Время - это прежде всего сумма темпоральных режимов, отражающих стадиальные характеристики системы как целого. И т.д.

«Золотой век» МРС пришелся на эпоху тотемизма и отчасти неолита - время родового и отчасти постродового индивида. Индивид «государственный» - это уже паллиативное и кризисное явление.

На ментальном/антропологическом уровне МРС - это система мышления, основанная на правополушарном доминировании, относительной целостности и монолитности, максимальном уровне синкретической сложности и минимальном - сложности комплексной, а также на сравнительно ограниченном наборе собственно культурных программ (помимо опосредованных культурой программ природных), не знающих меж собой глубоких конфликтов. Универсальность мифа как организующего контура в МРС проявляется в особой сегментарности мышления - воспроизводстве самостоятельной мифоматрицы в каждом секторе ментальности [Пелипенко 2017: 462-463].

Конец МРС наступает, когда разрушается (разрывается) экзистенциальная слитность человека с потоком бытия в его синкретической целостности. Однако мифоритаульный человек как культурно-антропологический тип имеет не историческое, а трансисторическое измерение. Он не исчезает в последующих эпохах. Основа индивида остается как ментальный фундамент, над которым надстраиваются этажи последующих систем, прежде всего логоцентрической.

МРС и ее носитель - индивид - полулатентно живет в любом современном обществе, и в ситуациях кризисного раскультуривания - сброса избыточных слоев культурной сложности - тектонические слои мифоритуальной архаики поднимаются на поверхность сознания, трансформируя и весь культурно-цивилизационный уклад (сразу в сознании всплывают «Исламское государство» и исламские фундаменталисты с их готовностью отрезать головы, стрелять по тысячелетним памятникам культуры и т.д., или Украина с отмороженными крайне правыми «националистами» и их мифами, зоологической жестокостью по отношению к иным и обслуживающими их квазиучеными и т.д. Да и нацистская Германия времен Третьего рейха пока не забыта! Правда, во всех этих случаях природа мифообразования несколько иная, скорее политическая, нежели в ситуации классического мифообразования.

Одна из ключевых мыслей А. Пелипенко состоит в том, что обращение к эпохе МРС - не отвлеченная академическая штудия, не имеющая отношения к современности. Последняя вплотную подошла к вопросу о техногенном изменении человеческой природы. Изменения эти уже идут, но пока под воздействием экосреды. На очереди уже и сознательное вмешательство в геном и имплантирование в организм микрочипов. В очередной раз возникает угроза вмешательства в, мягко говоря, не до конца понятую систему. Последствия могут быть еще более катастрофическими, нежели «покорение природы» самонадеянной позитивистской наукой в прошлом и позапрошлом веках. Теория культуры, развернутая, в частности, на примере МРС, не страхует от роковых решений, но, по меньшей мере, позволяет лучше понять систему, в которую сциентистский интеллект готов в очередной раз вторгнуться. Но и без этого очевидно - чем лучше мы узнаем прошлое, тем тревожнее становится заглядывать в будущее. Но именно на пути постижения своего прошлого современного человека ждут самые ошеломляющие открытия. 
Впрочем, пожалуй, достаточно. В кратком обзоре трудно передать все богатство идей, содержащихся в книге А. Пелипенко. Некоторые из них, здесь не упомянутые, просто перечислю.

Это и его мысль о неолитическом синтезе (середина - конец V тыс. до н.э. до рубежа IV-III тыс. до н.э.), когда произошел прорыв к цивилизации с присущими ей атрибутами урбанизации, письменности и государственности. В основе этого синтеза, показывает А. Пелипенко, лежат вовсе не изменения среды обитания, технологий производства и жизнеобеспечения и не фатально предопределенное абстрактно-прогрессивное развитие вообще, а гендерная проблема, соединение двух альтернативных жизнеустроительных принципов (женского и мужского).

Это и идея культуры как полевого образования (разд. I, гл. 3), которая хотя и не нова и имеет обширную литературу, но А. Пелипенко придает этой проблеме статус развернутой концепции, согласно которой культура вообще и локальные культурные системы в частности по глубинной своей онтологии суть полевые образования (структуры), в числе свойств которых - способность к нелокальным воздействиям [Пелипенко 2017: 134]. Культурное поле, согласно А. Пелипенко, представляет собой гетерогенную среду, в которой действуют разные по своей силе, плотности и направленности, направленности и устойчивости во времени интенционально-энергетические потоки, генерируемые ментальностью человеческих индивидуумов или групп [Пелипенко 2017: 144].

Исключительно содержательны и жестко подчинены общей логике автора размышления об эволюционной динамике в свете медиационной парадигмы (разд. I, гл. 4), о системных константах мифоритуальной системы культуры (разд. II), о мифоритуальном пространственно-временном континууме (разд. II, гл. 2), о феномене магии и его атрибутах (разд. II, гл. 3) и др.

Лично меня остро занимает вопрос: отчего Россия, обладая всеми возможными ресурсами, богатейшей историей и культурой, сегодня стагнирует, развивается ни шатко ни валко, слабо модернизируется, особенно экономика? Да и социокультура и политика тоже. Поэтому освоение этого и других трудов А. Пелипенко шло под знаком этого неизбывного вопроса, который, уверен, занимает далеко не только меня. Улавливая в целом парадигматику автора и суть его смыслогенетической теории культуры, я-таки «выудил» из его текстов практически прямое указание на это обстоятельство. Вот оно: «в каждом обществе социокультурная динамика напрямую зависит от того, насколько соответствующая мифоритуальная традиция способна воспроизводить свои космоорганизующие принципы в материале инновативных специализаций. Если же не способна инновации, при всей их практической привлекательности и даже жмизненной необходимости, не приживаются» [Пелипенко 2017: 211] (курсив мой. - О.М. Есть, разумеется, и другие подобные свидетельства в других местах и трудах А. Пелипенко). Если это так, то вывод для российского общества и его социокультуры довольно пессимистичный, хотя трудно с ним примириться.

Чтение трудов А. Пелипенко - непростое занятие, требующее немалого интеллектуального напряжения. Дело не в том, что язык его сложен, нет. Язык как раз понятен и точен, хотя автор и вводит множество новых для социальногуманитарного знания понятий и терминов. Сложны и непривычны сами мысли, которым к тому же тесно в рамках повествования. Этих мыслей много, что придает исследованию впечатляющую многомерность и полифонию.

А. Пелипенко своим трудом продемонстрировал органичное соединение социально-гуманитарного и естественнонаучного знания, в очередной раз задав исключительно высокий теоретический и методологический уровень и образец того, каким должно быть исследование всего происходящего в обществе и с обществом. Причем блестяще сделал это на примере анализа вполне конкрет- 
ного и, казалось бы, далекого от проблем и реалий современности явления мифоритуальной системы культуры. Его исследование совершенно лишено бессодержательных рассуждений, абстрактных и недоказуемых утверждений и уж тем более - словоблудия (в отличие от бесчисленного множества отечественных и зарубежных публикаций социально-гуманитарного характера). Вызывающая сожаление редкость подобного уровня и масштаба исследований делает труд А. Пелипенко еще более уникальным и оригинальным. Научное сообщество России, безусловно, может гордиться им.

И еще раз: исключительно важно опубликовать вообще все то, что еще не опубликовано из творчества А. Пелипенко. Пусть даже в отрывочных заметках, пусть даже пунктирно. Возможно, в этих набросках, сгруппированных согласно хоть какой-то логике, окажутся идеи, которые, несомненно, стимулируют новые поколения исследователей к дальнейшим поискам и смогут быть развитыми в том или ином виде учеными, проникнувшимися новаторским научным духом и строем парадигматики А. Пелипенко. Я совершенно уверен, что подобные публикации будут востребованы научным сообществом и получат свое продолжение в трудах его последователей.

\section{Список литературы}

Митрошенков О.А. 2015а. Какие смыслы формирует современная культура? - Власть. № 9. С. 200-207.

Митрошенков О.А. 2015б. Фундаментальная книга о культуре, которую следует прочитать. - Управление мегаполисом. № 4. С. 61-72.

Пелипенко А.А. 2012. Постижение культуры. В 2 ч. Ч. 1. Культура и смысл. М.: РОССПЭН. 608 с.

Пелипенко А.А. 2017. Постижение культуры. В 2 ч. Ч. 2. Мифоритуальная система. Кн. 1. Медиационная парадигма. 2017. М.: РОССПЭН; Ельцин-центр. $502 \mathrm{c}$.

MITROSHENKOV Oleg Aleksandrovich, Dr.Sci. (Philos.), Professor; Professor of the Chair of UNESCO, Institute of Public Administration; Professor of the Chair of Management and World Economy and International Relations, Institute of Business and Business Administration, Russian Presidential Academy of National Economy and Public Administration (bld.8, 84 Vernadskogo Ave, Moscow, Russia, 119571; omitrosh6@mail.ru)

\section{MIFORITUAL SYSTEM IN OPTICS OF THE SEMANTIC- GENETIC THEORY OF CULTURE BY A. PELIPENKO}

\footnotetext{
Abstract. The article deals with the second part of the fundamental work of the Russian scientist-culturologist Andrei Pelipenko "Comprehension of History" - "Miforitual system». Book 1. "Mediation paradigm» (2017). The author applies his semantic-genetic theory of culture to the analysis of general and systemic characteristics of the mythical system - the first of two fully realized in the history of cultural macrosystems. The book interprets the co-evolution of the immanent development of man as a cultural being and his external collective history - the history of the system and institutional structures of culture. The analysis is carried out on the base of mediation paradigm, which refers to quantum mechanics, to cosmological, biological, neurophysiological and mental slices of reality. The key provisions of the mediation paradigm are the concepts of the ontological status of the transcendent world and the field properties of culture.

The author leaves no stone unturned from the paradigmatics of the general scientific discourse, which is positivist in its essence and reflects, despite being equipped with the latest post-non-classical ideas, the view of the world of the $19^{\text {th }}$ century with its inherent prejudices of vulgar-mechanistic rationalism.

Keywords: culture, sense, sense-genetic theory, miforitual system, mediation paradigm, psychosphere mediation, implicative world, beyond world, culture as field education, myth, ritual, miforitual space-time continuum, magema
} 